\title{
Impact of COVID-19 on hospitalization, death rate, and other inpatient measures among Asian patients in hospitals in California
}

\author{
Luong Ly ${ }^{1,2}$, Thida Win ${ }^{3}$, Jessica Mantilla ${ }^{4}$, Ching-Hsiu Chiu*1, Allan Leung ${ }^{1}$, Chia-Hsing Yeh ${ }^{1}$, Wen-Hsiang Teng ${ }^{1}$, \\ Su-Yen $\mathrm{Wu}^{1}$, Stanley Toy ${ }^{1}$, Wen-Ta Chiu ${ }^{1,5}$, Jonathan $\mathrm{Wu}^{6}$ \\ ${ }^{1}$ COVID-19 Team, AHMC Health System, 500 E Main St, Alhambra, United States \\ ${ }^{2}$ The Joint Commission, 1 Renaissance Blvd, Oakbrook Terrace, United States \\ ${ }^{3}$ Department of Infection Disease, Garfield Medical Center, United States \\ ${ }^{4}$ Department of Infection Control, Alhambra Hospital Medical Center, United States \\ ${ }^{5}$ Taipei Medical University, Taiwan, ROC \\ ${ }^{6}$ AHMC Health System, United States
}

Received: October 11, 2021

Accepted: December 2, 2021

Online Published: December 13, 2021

DOI: $10.5430 /$ jha.v10n5p31

URL: https://doi.org/10.5430/jha.v10n5p31

\begin{abstract}
Objective: This study aims to analyze COVID-19 hospitalization and death rate in the Asian population of a predominantly Asian-serving multi-hospital system (ASMHS).

Methods: The COVID-19 patient information was collected electronically from March 1 to November 12, 2020, including demographics, insurance, mortality, ICU admissions, and length of stay (LOS). Demographic characteristics were compared with the county-level and national data. A comparison of hospital LOS between Asians and non-Asians was conducted.

Results: The prevalence ratio of deaths in Asians at ASMHS was 1.29, which was 53\% higher than the county and $77 \%$ higher than the nation. The ICU admission for ASMHS Asian patients was 11.8\% compared to 5.6\% for non-Asian. Overall Asians and Asians aged $>65$ had significantly longer LOS than non-Asians $(p<.001)$.

Conclusions: High prevalence ratio of deaths was noted in ASMHS's Asian patients which may be related to older age, higher ICU rate, and longer LOS.
\end{abstract}

Key Words: COVID-19, Hospitalization, Hospital length of stay, Asian population, ICU admissions

\section{INTRODUCTION}

The Coronavirus Disease 2019 (COVID-19) outbreak has been continuously spreading worldwide at an unprecedented pace. In the United States, COVID-19 has infected more than 26 million people, leading to approximately 440,000 deaths as of January 31, 2021. ${ }^{[1]}$ Since the beginning of the pandemic, published studies have shown that different racial groups have been affected to varying degrees in the United States. ${ }^{[2-4]}$ However, the literature review suggests that the overall number and percentage of Asian-Americans included are often low, with a possible association with discrimination and underrepresentation. ${ }^{[5,6]}$ Thus, it may not reflect the reality of its impact on the Asian-American community.

\footnotetext{
*Correspondence: Ching-Hsiu Chiu; Email: Ssahmc2@ gmail.com; Address: AHMC Health System COVID-19 Team, 500 E Main St, Alhambra, CA 91801, United States.
} 
The studied geographic area (SGA) is a 284-square-mile community located in Southern California, consisting of more than 1.4 million residents and 47 cities and neighborhoods. The area consists of a diverse population of $46 \%$ Latino, $28 \%$ Asian, 22\% White, $4 \%$ Black, and $1.4 \%$ Other. ${ }^{[7]}$ The SGA has a uniquely large Asian-American population, numbering over half of a million, totaling one-third of all AsianAmericans residing in the county. ${ }^{[8,9]}$ This large population of Asian-Americans (hereafter abbreviated to Asians) in the SGA provides an opportunity to study COVID-19's impact on Asians in the United States.

The study was conducted in a predominantly Asian-serving multi-hospital system (ASMHS), a network of ten community hospitals with approximately 1,400 hospital beds and 3,000 affiliated physicians which is one of the main hospital systems serving the SGA. Asian patients accounted for $30 \%$ of all inpatient admissions at ASMHS hospitals during the time of our data collection. This closely resembles the Asian makeup of the SGA.

The first objective was to compare hospitalization and death rates within ASMHS with county-level and national-level data. The second objective of this study was to assess and compare the inpatient measures of ICU admission and hospital length of stay (LOS) in Asian COVID-19 patients versus other racial groups within ASMHS. We hope this study can provide insight into the effects of COVID-19 on the Asian community.

\section{Methods}

We performed a retrospective review of all the COVID-19 cases in ASMHS, targeting six geographically located hospitals in the SGA. COVID-19 cases were identified by positive qualitative polymerase-chain-reaction (PCR) assays. We collected data of hospitalized COVID-19 patients through the electronic medical record (EMR) system from March 1, 2020, to November 12, 2020, and included sex, age, race, insurance type, mortality, ICU admissions, and hospital length of stay (LOS). County-level and national level comparisons were collected based on public data from the county public health jurisdictions, the Centers for Disease Control and Prevention (CDC), and the United States Census Bureau as of January $31,2021 .^{[10-14]}$

Demographic data in ASMHS were abstracted from the EMR system and assembled into a uniform database. Insurance type was classified as Medicaid, Medicare, private or selfpay, and no insurance (including charity care). Sex was self-reported as male and female. Age was divided into the four following groups: 0 to 17 years, 18 to 49 years, 50 to 64 years, and 65 years and older. The race was self-reported and categorized through the hospital's patient information collection form as White, Asian, Black, and Other; we combined all racial groups (White, Black, and Other) other than Asian as the non-Asian group, and compared hospital LOS with the Asian group. Death cases were collected based on the use of expiration discharge code (coded EXP) in addition to COVID-19 diagnosis.

Hospitalized COVID-19 patients' demographic characteristics in ASMHS were presented through descriptive statistics and conducted in Microsoft Excel 2016. A two-sample $z$-test was conducted to compare hospital LOS between Asians and non-Asians by subgroups of different demographic characteristics. We identified statistical significance when the $p$-value was less than .005 , representing a $99.5 \%$ confidence level.

The Institutional Review Board (IRB) of our institution has determined that the IRB review and approval are not required for this study (IRB \# IRB00012868/IORG0010770).

\section{RESULTS}

Congregating the EMR data from the six hospitals targeted in this study, there were a total of 3,734 COVID-19 patients, representing $10.7 \%$ of total patients in ASMHS ( $\mathrm{N}=$ 35,033) from March 1, 2020, to November 12, 2020. Among ASMHS's 3,734 COVID-19 patients, there were 42.3\% Medicaid (Medi-Cal) patients, $38.5 \%$ private or self-pay patients, $13.0 \%$ Medicare patients, and $6.2 \%$ uninsured or charity care patients. The demographic characteristics of COVID-19 hospitalized patients were comparable with the county and the nation, where a similar period of data was collected from March 1, 2020, to November 30, 2020. For the breakdown of sex, ASMHS had 50.4\% male and $49.6 \%$ female hospitalized COVID-19 patients, which slightly differed from the county ( $48.3 \%$ male; $51.7 \%$ female) but was similar to the nation (50.8\% male; $49.2 \%$ female). By age groups, ASMHS had more hospitalized patients who were 18 to 49 years (47.3\%) and had fewer hospitalized patients who were 65 years and older (23.7\%) compared with the county (32.7\%) and the nation (43.2\%). Regarding race, ASMHS had a higher proportion of Asian COVID-19 hospitalized patients (15.4\%) compared with the county (4.0\%) and the nation (5\%).

The demographic characteristics of COVID-19 death cases were also comparable with the county and the nation, where the data were collected as of January 31, 2021. ASMHS had a total of 292 deaths, of which $60.6 \%$ were male and $39.4 \%$ were female, similar to the county $(58.7 \%$ male; $41.3 \%$ female) and the nation ( $54.1 \%$ male; $45.9 \%$ female). By age groups, ASMHS also had a similar pattern of having the highest death rate for those 65 years and older (74.7\%) compared with the county $(71.8 \%)$ and the nation $(81.1 \%)$. By 
race, ASMHS had a higher proportion of Asian COVID-19 deaths $(36.3 \%)$ compared with the county $(13.0 \%)$ and the nation $(4.3 \%)$.

A prevalence ratio is defined as the ratio of the proportion of persons with the disease over the proportion with exposure. In our data, this was calculated by dividing the proportion of hospitalization or death over the proportion of that group in the population. Table 1 lists all prevalence ratios calculated from ASMHS, the county, and the nation. A prevalence ratio of less than one indicates that the prevalence of hospitalization or death is lower than expected in that population subset. All prevalence ratios for Asian hospitalization from ASMHS, the county, and the nation were less than one. However, the prevalence ratio of deaths in Asians at ASMHS was 1.29, which was $53 \%$ higher than the prevalence ratio of deaths in Asians seen in the county (0.84) and $77 \%$ higher than the prevalence ratio nationally $(0.73)$.

Table 1. ASMHS Asian COVID-19 patients' proportion of population, hospitalization and deaths compared with the county and the nation ${ }^{[10,12,14]}$

\begin{tabular}{|c|c|c|c|c|c|}
\hline & \multirow{2}{*}{$\begin{array}{c}\text { Population, } \\
\text { Asian \% }\end{array}$} & \multicolumn{2}{|c|}{ Hospitalization, Asian } & \multicolumn{2}{|c|}{ Death, Asian } \\
\hline & & COVID-19 Proportion & Prevalence Ratio* $^{*}$ & COVID-19 Proportion & Prevalence Ratio $^{* *}$ \\
\hline ASMHS & $28.0 \%$ & $15.4 \%$ & 0.55 & $36.3 \%$ & 1.29 \\
\hline County $^{10}$ & $15.4 \%$ & $4.0 \%$ & 0.26 & $13.0 \%$ & 0.84 \\
\hline Nation $^{12}$ & $5.9 \%$ & $5.1 \%$ & 0.86 & $4.3 \%$ & 0.73 \\
\hline
\end{tabular}

Note. ${ }^{10}$ County-level data were collected from the County Department of Health Services, representing 70 designated 9-1-1 receiving hospitals' daily self-report data, from March 1, 2020, to November 30, 2020. ${ }^{12}$ United States nation-level data were collected from the Centers for Disease Control and Prevention, from March 1, 2020, to January 31, 2021. ${ }^{14}$ Population data were collected from the U.S. Census Bureau Population estimates, July 1, 2019, and the SGA Asian proportion of the population was used for ASMHS. "Prevalence ratio is calculated by dividing the proportion of hospitalization or death over the proportion of the population.

Table 2. Comparison of ASMHS's characteristics of all hospitalized and ICU admitted COVID-19 patients between Asain and non-Asian patients

\begin{tabular}{|c|c|c|c|c|}
\hline & \multicolumn{2}{|c|}{ Asian $(n=575)$} & \multicolumn{2}{|c|}{ Non-Asian $(n=3,159)$} \\
\hline & $\mathbf{n}$ & $\%$ & n & $\%$ \\
\hline \multicolumn{5}{|c|}{ All hospitalizations $(\mathrm{N}=\mathbf{3 , 7 3 4})$} \\
\hline \multicolumn{5}{|l|}{ Sex } \\
\hline Male & 269 & $46.8 \%$ & 1,576 & $50.1 \%$ \\
\hline Female & 306 & $53.2 \%$ & 1,571 & $49.9 \%$ \\
\hline \multicolumn{5}{|l|}{ Age } \\
\hline $0-17$ & 2 & $0.3 \%$ & 153 & $4.8 \%$ \\
\hline $18-49$ & 146 & $25.4 \%$ & 1,605 & $50.8 \%$ \\
\hline $50-64$ & 157 & $27.3 \%$ & 787 & $24.9 \%$ \\
\hline $65+$ & 270 & $47.0 \%$ & 614 & $19.4 \%$ \\
\hline \multicolumn{5}{|c|}{ ICU admissions ( $N=247)$} \\
\hline \multicolumn{5}{|l|}{ Sex } \\
\hline Male & 42 & $61.8 \%$ & 111 & $62.0 \%$ \\
\hline Female & 26 & $38.2 \%$ & 68 & $38.0 \%$ \\
\hline \multicolumn{5}{|l|}{ Age } \\
\hline $0-17$ & 0 & $0.0 \%$ & 0 & $0.0 \%$ \\
\hline $18-49$ & 0 & $0.0 \%$ & 26 & $14.5 \%$ \\
\hline $50-64$ & 9 & $13.2 \%$ & 48 & $26.8 \%$ \\
\hline $65+$ & 59 & $86.8 \%$ & 105 & $58.7 \%$ \\
\hline
\end{tabular}


Table 3. ASMHS's hospital LOS of Asian COVID-19 patients compared with non-Asian COVID-19 patients

\begin{tabular}{lcccccc}
\hline \multirow{2}{*}{ Hospital Length of Stay } & \multicolumn{2}{c}{ Asian $(\mathbf{N}=\mathbf{5 7 0})$} & & \multicolumn{2}{c}{ Non-Asian $(\mathbf{N}=\mathbf{3 , 1 4 0})$} & \multirow{2}{*}{$\boldsymbol{p}$-value } \\
\cline { 2 - 3 } \cline { 5 - 6 } & $\mathbf{n}$ & Days, mean & & $\mathbf{n}$ & Days, mean & \\
\hline All & 570 & 6.2 & & 3,140 & 3.6 & $<.001^{*}$ \\
Sex & & & & & & \\
$\quad$ Male & 268 & 6.6 & & 1,578 & 4.1 & $<.001^{*}$ \\
$\quad$ Female & 302 & 5.8 & & 1,562 & 3.1 & $<.001^{*}$ \\
Age & & & & & \\
$0-17$ & 2 & 1.0 & & 137 & 1.0 & N/A $^{* *}$ \\
$18-49$ & 143 & 1.8 & & 1,608 & 2.1 & .063 \\
$50-64$ & 155 & 5.0 & & 785 & 4.2 & .293 \\
$65+$ & 270 & 9.2 & & 610 & 7.1 & $<.001^{*}$ \\
\hline
\end{tabular}

Note. ${ }^{*}$ There was statistical significance found when p-value $<0.005$, under a $99.5 \%$ confidence level. ${ }^{* *}$ The data sample size was not big enough to undergo statistical testing.

For a closer examination of the uniquely higher proportion of Asian COVID-19 patients at ASMHS, Table 2 compared our hospitalized COVID-19 patients' characteristics by sex, age, and ICU admissions between Asian and non-Asian (defined by all other racial groups combined). There were a total of 575 Asian COVID-19 patients and 3,159 non-Asian patients, of which Asians had a higher proportion of females (53.2\%) than non-Asian (49.9\%). By age group, Asians had the highest proportion at 65 years and older $(47.0 \%)$, and non-Asian had the highest proportion at 18-49 years old (50.8\%). By insurance type, both Asian and non-Asian had the most private or self-pay patients $(43.5 \% ; 37.3 \%)$. Asian had more Medicare patients and non-Asian had more Medicaid patients. We further compared Asian and non-Asian by ICU admissions. Asian and non-Asian shared a similar sex distribution for ICU admissions, but Asians had a more elderly-skewed age group distribution than non-Asian. Of the 575 Asian COVID19 patients, 68 were admitted to the ICU (11.8\%), and for non-Asian ASMHS COVID-19 patients, 179 out of 3,159 patients went into the ICU (5.6\%).

Table 3 compared ASMHS's hospital length of stay (LOS) between Asian and non-Asian COVID-19 patients. There were 570 Asian and 3,140 non-Asian patients available for this comparison. We found that Asians overall had significantly longer LOS than non-Asian $(6.2 ; 3.6 ; p<.001)$ as well as Asian males versus non-Asian males $(6.6 ; 4.1 ; p<$ $.001)$ and Asian females versus non-Asian females (5.8; 3.1; $p<.001)$. By age group, Asians aged 65 years and older had significantly longer hospital LOS than non-Asian (9.2; 7.1; $p$ $<.001)$.

\section{Discussion}

Our results show the prevalence ratios for hospitalization in Asians were lower than 1 for ASMHS, the county, and the nation. This suggests that Asians hospitalized due to COVID-19 were not disproportionately higher compared to the prevalence of Asians in that geographic region. According to a survey published in January $2021,{ }^{[15]}$ Asians were one of the minority groups that had higher adherence to mask-wearing mandates. The effectiveness of mask-wearing in the prevention of COVID-19 has been proven with multiple studies, ${ }^{[16,17]}$ We surmise this higher mask-wearing may contribute to a lower prevalence ratio of hospitalization among the Asian population in the SGA, the county, and the nation as a whole. In addition, 59\% of Asian-Americans were born in Asia nationwide, and an even higher percentage $(67 \%)$ of Asian-Americans in SGA were immigrants. ${ }^{[9,18]}$ Asian countries have been known to have higher rates of mask-wearing in the world, ${ }^{[19,20]}$ even before the COVID-19 pandemic partly due to experience with previous viral outbreaks such as the 2002-2004 SARS outbreak which predominantly affected Asian countries. ${ }^{[21]}$ This high percentage of immigration from home countries where mask-wearing is widely accepted further explains lower rates of COVID-19 hospitalization seen in Asians in our study.

Our analysis found a prevalence ratio of deaths among Asian COVID-19 patients in ASMHS (1.29) that was significantly higher than the county and the nation. This is likely due to the age and health of these patients. Of the deaths who were Asian that occurred at ASMHS, $88.6 \%$ were in the 65-yearold or above age group. Many of these patients were from residential or skilled nursing facilities (SNFs). There are a total of 335 SNFs in the county. ${ }^{[22]}$ More than 70 SNFs are located in the SGA alone representing $20.9 \%$ of all SNFs in the county. Cumulative COVID-19 positive cases in these facilities totaled more than 3,000 with COVID-19 related resident deaths totaling more than 570 . SNFs and residential facilities have a higher association with multiple risk factors that more easily lead to COVID-19 mortality. ${ }^{[23-25]}$ ASMHS, 
in addition to serving the large surrounding Asian population, also covers a high number of surrounding SNFs. Many of these SNFs are Asian-based and Asian-owned contributing to the high numbers of older and likely sicker Asian patients. ${ }^{[26]}$

ICU admission and hospital LOS are indicators of increased severity and mortality. ${ }^{[27,28]}$ ASMHS's data reflects that Asian COVID-19 patients were almost twice as likely to be admitted to the ICU when compared to non-Asian patients $(11.8 \%$ vs. $5.6 \%)$ and have a significant increase in hospital LOS (6.2 days vs. 3.6 days in non-Asians). Asian seniors 65 or older have an even higher difference in LOS (9.2 days vs. 7.1 days in non-Asians). All the above factors may contribute to the higher prevalence ratio of Asian deaths seen at ASMHS compared to the county and the nation.

Male and female distribution in COVID-19 hospitalization was approximately 1:1. This was observed in ASMHS, the county, and the nation. The deaths from COVID-19 at ASMHS were predominantly male $(60.6 \%)$ while females made up $39.4 \%$. This roughly $6: 4$ ratio is observed also at the county level as well as globally with the male gender being a risk factor for severe COVID-19 as well death from COVID19. ${ }^{[29-31]}$ This similar distribution can also be observed in ICU admission data in both Asian and non-Asian ASMHS COVID-19 patients, further supporting COVID-19's disproportionate effect on the male gender.

\section{Limitation}

This was a retrospective study and as such had limitations we had to work with such as limited or incomplete data. Other limitations of this study included incomplete or inaccessible data at the county as well as national levels. Only partial county-level hospitalization data was found to make our comparisons. The national COVID-NET hospitalization data was limited to 250 hospitals in 14 states and only $74 \%$ of total deaths were available with demographic data from the CDC. Therefore, data may not fully reflect actual hospitalizations and deaths. For direct comparison purposes, COVID-19 hospitalization data of SGA would have been ideal. However, we were unable to access this information. Also, data col- lection time frames from different sources were not always consistent. This may contribute to bias in our comparisons. COVID-19 is known to be more fatal to those with medical comorbidities or pre-existing conditions. The higher Asian death prevalence ratio seen at ASMHS may have been due to a higher percentage of people with comorbidities but this was not a variable we were able to measure. Patient readmission and its relation to LOS may have also impacted the death prevalence ratio. However, these data were not available for us to eliminate as confounding variables.

\section{Conclusions}

This study from ASMHS provides a unique opportunity to observe COVID-19 hospitalization and death in the Asian population in SGA. Asian COVID-19 hospitalization rate at ASMHS (15.4\%) was lower than the proportion of the Asian population in SGA (28\%). However, the prevalence ratio in deaths in ASMHS's Asian COVID-19 patients was 53\% higher than Asian COVID-19 deaths seen in the county as a whole. In addition, Asian COVID-19 patients at ASMHS were twice as likely to be admitted to the ICU and their length of stay was significantly longer compared to that of non-Asians. We surmise both of these observations were due to a high number of elderly patients (age $>65$ ). This study highlights the disproportionately high death rates among Asians affected by COVID-19 at ASMHS and we hope this can contribute to the formulation of strategies to mitigate risks in vulnerable populations.

\section{ACKNOWLEDGEMENTS}

The authors would like to thank all facilities and staff of AHMC Health System involved with the research and writing of this document.

\section{FUNDING}

The authors received no financial support for the research, authorship, and/or publication of this article.

\section{Conflicts of Interest Disclosure}

The authors declare they have no conflicts of interest.

\section{REFERENCES}

[1] Centers for Disease Control and Prevention. United States COVID19 Cases, Deaths, and Laboratory Testing (NAATs) by State, Territory, and Jurisdiction. Accessed September 30, 2021. Available from: https://covid.cdc.gov/covid-data-tracker/index .html\#cases_casesper100klast7days

[2] Abuelgasim E, Saw LJ, Shirke M, et al. COVID-19: Unique public health issues facing Black, Asian and minority ethnic communi- ties. Current Problems in Cardiology. 2020; 45(8):100621. PMid: 32448759. https://doi.org/10.1016/j.cpcardiol.2020.1 00621

[3] Gemelas J, Davison J, Ing S. Inequities in employment by race, ethnicity, and sector during COVID-19. Journal of Racial and Ethnic Health Disparities. 2021; 1-6. PMid: 33452573. https : //doi.org/10.1007/s40615-021-00963-3

[4] Hooper MW, Nápoles AM, Pérez-Stable EJ. COVID-19 and 
racial/ethnic disparities. JAMA. 2020 Jun 23; 323(24): 2466-7. PMid: 32391864. https://doi.org/10.1001/jama.2020.8598

[5] Yehia BR, Winegar A, Fogel R, et al. Association of race with mortality among patients hospitalized with coronavirus disease 2019 (COVID-19) at 92 US hospitals. JAMA Network Open. 2020; 3(8): e2018039. PMid: 32809033. https://doi.org/10.1001/jama networkopen. 2020.18039

[6] Ruiz NG, Horowitz JM, Tamir C. Many Black and Asian Americans say they have experienced discrimination amid the COVID-19 outbreak. Pew Research Center. 2020; 1. Available from: https:// www . pewsocialtrends.org/wp-content/uploads/sites/3 /2020/07/PSDT_07.01.20_racism.covid_Full.Report.pdf

[7] Los Angeles Times. Mapping L.A. The San Gabriel Valley. Accessed October 6, 2021. Available from: http://maps . latimes . com/n eighborhoods/region/san-gabriel-valley/

[8] Asian Americans Advancing Justice-Los Angeles (2018). A Community of Contrasts, Asian Americans, Native Hawaiians and Pacific Islanders in the San Gabriel Valley. Accessed October 1, 2021. Available from: https://www.advancingjustice-la.org/sites/defa ult/files/A_Community_of_Contrasts_SGV_2018.pdf

[9] Jones NA, Chief RS. The Asian population in the United States: Results from the 2010 census. Inmeeting of the 2010 Asian Profile America Event, Washington, DC 2012 May 2. Accessed October 1, 2021. Available from: https://www.ssa.gov/people/aapi/ma terials/pdfs/2010census-data.pdf

[10] Los Angeles Department of Health Services. COVID-19 Information Health Services Dashboard. Accessed October 2, 2021. Available from: https://dhs.lacounty.gov/

[11] Los Angeles County Department of Public Health. LA County Daily COVID-19 Data. Accessed October 2, 2021. Available from: http://publichealth.lacounty.gov/media/corona virus/data/index.htm

[12] Centers for Disease Control and Prevention. COVID Data Tracker. Accessed October 2, 2021. Available from: https://www.cdc.gov/coronavirus/2019-ncov/covid-d ata/covidview/index.html

[13] Centers for Disease Control and Prevention. COVID-19 LaboratoryConfirmed Hospitalizations. Accessed October 2, 2021. Available from: https://gis.cdc.gov/grasp/COVIDNet/COVID19_5.h tml

[14] United States Census Bureau. Population estimates, July 1, 2019, (V2019), QuickFacts, Los Angeles County, California. Accessed October 2, 2021. Available from: https://www . census .gov/qui ckfacts/losangelescountycalifornia

[15] Hearne BN, Niño MD. Understanding how race, ethnicity, and gender shape mask-wearing adherence during the COVID-19 pandemic: evidence from the COVID impact survey. Journal of Racial and Ethnic Health Disparities. 2021 Jan 19; 1-8. PMid: 33469866. https://doi.org/10.1007/s40615-020-00941-1

[16] Chu DK, Akl EA, Duda S, et al. Physical distancing, face masks, and eye protection to prevent person-to-person transmission of SARS CoV-2 and COVID-19: a systematic review and meta-analysis. The Lancet. 2020; 395(10242):1973-87. https ://doi .org/10.1016/ s0140-6736 (20) 31142-9

[17] Solia E, Angelis S, Maglara E, et al. The Role of Surgical Masks during the COVID-19 Pandemic. A Mini-Review. Journal of Long-Term Effects of Medical Implants. 2020; 30(4). PMid: 33463923. https://doi.org/10.1615/jlongtermef fmedimp lants. 2020036883
[18] Lopez G, Ruiz NG, Patten E. Key facts about Asian Americans, a diverse and growing population. Pew Research Center. Accessed October 3, 2021. Available from: https://www . pewresearch.org/fact-tank/2021/04/29/k ey-facts-about-asian-americans/

[19] Zhong BL, Luo W, Li HM, et al. Knowledge, attitudes, and practices towards COVID-19 among Chinese residents during the rapid rise period of the COVID-19 outbreak: a quick online cross-sectional survey. International Journal of Biological Sciences. 2020; 16(10): 1745. PMid: 32226294. https://doi.org/10.7150/ijbs . 45221

[20] Hsu $\mathrm{CH}$, Chen $\mathrm{CH}$, Huang HT, et al. To safely reopen after a lockdown, masks are crucial: lessons from Taiwan. Public Health. 2021; 190: 99. PMid: 33385641. https://doi.org/10.1016/j.puhe .2020 .06 .027

[21] Centers for Disease Control and Prevention. CDC SARS Response Timeline. Accessed October 5, 2021. Available from: https : //ww w.cdc.gov/about/history/sars/timeline.htm

[22] Los Angeles County Department of Public Health. COVID-19 Dashboard for Skilled Nursing Facilities. Accessed October 4, 2021. Available from: http://publichealth.lacounty.gov/snfdas hboard.htm

[23] Caffrey C. Residents living in residential care facilities: the United States, 2010. National Center for Health Statistics; 2012. Available from: https://pubmed.ncbi.nlm.nih.gov/22617169/

[24] Rutten JJ, van Loon AM, van Kooten J, et al. Clinical suspicion of COVID-19 in nursing home residents: symptoms and mortality risk factors. Journal of the American Medical Directors Association. 2020; 21(12): 1791-7. PMid: 33256958. https://doi.org/10.1 $016 / j \cdot j$ amda. 2020.10 .034

[25] Panagiotou OA, Kosar CM, White EM, et al. Risk factors associated with all-cause 30-day mortality in nursing home residents with COVID-19. JAMA Internal Medicine. 2021; 181(4): 439-48. PMid: 33394006. https : //doi .org/10.1001/jamainternmed. 2020.7968

[26] Wang J. More Chinese in San Gabriel Valley living in assisted living facilities. Alhambra Source. Accessed October 4, 2021. Available from: https://www.alhambrasource.org/more-chinese-i n-san-gabriel-valley-living-in-assisted-living-fac ilities

[27] Di Fusco M, Shea KM, Lin J, et al. Health outcomes and economic burden of hospitalized COVID-19 patients in the United States. Journal of Medical Economics. 2021; 24(1): 308-17. PMid: 33555956. https://doi .org/10.1080/13696998.2021.1886109

[28] Yang X, Yu Y, Xu J, et al. Clinical course and outcomes of critically ill patients with SARS-CoV-2 pneumonia in Wuhan, China: a singlecentered, retrospective, observational study. The Lancet Respiratory Medicine. 2020; 8(5): 475-81. https://doi.org/10.1016/s221 3-2600 (20) 30079-5

[29] Viveiros A, Rasmuson J, Vu J, et al. Sex differences in COVID-19: candidate pathways, genetics of ACE2, and sex hormones. American Journal of Physiology-Heart and Circulatory Physiology. 2021; 320(1): H296-304. PMid: 33275517. https://doi .org/10.115 2/ajpheart.00755.2020

[30] Xiang G, Xie L, Chen Z, et al. Clinical risk factors for mortality of hospitalized patients with COVID-19: systematic review and metaanalysis. Annals of Palliative Medicine. 2021. PMid: 33549005. https://doi.org/10.21037/apm-20-1278

[31] Biswas M, Rahaman S, Biswas TK, et al. Association of sex, age, and comorbidities with mortality in COVID-19 patients: a systematic review and meta-analysis. Intervirology. 2021; 64(1): 36-47. PMid: 33296901. https://doi.org/10.1159/000512592 